Running head: ASIAN AMERICANS' SUICIDAL IDEATION

Risk and Protective Factors Associated With Asian American Students' Suicidal Ideation:

A Multi-Campus, National Study

Y. Joel Wong, Indiana University Bloomington

Christopher Brownson, The University of Texas at Austin

Alison E. Schwing, Indiana University Bloomington

Wong, Y. J., Brownson, C., \& Schwing, A. E. (2011). Risk and protective factors associated with Asian American students' suicidal ideation: A multi-campus, national study. Journal of College Student Development, 52, 396-408. 


\begin{abstract}
The purpose of this study was to examine risk and protective factors associated with suicidal ideation among 1,377 Asian American college students' across 66 campuses. The results indicated that medication for mental health concerns, gender, GPA, undergraduate status, religious affiliation, living with a family member, living with a partner, and active participation in student organizations were associated with morbid thoughts. Furthermore, medication for mental health concerns, undergraduate status, living with family, and active participation in student organizations were related to serious consideration of suicide. Among Asian Americans who seriously considered suicide in the past 12 months, recent family, academic, and financial problems were the top three most frequently endorsed events occurring before the development of suicidal ideation.
\end{abstract}


Risk and Protective Factors Associated With Asian American Students' Suicidal Ideation:

\section{A Multi-Campus, National Study}

Suicidal behavior is a major mental health risk among U.S. college students and is the second leading cause of death among this demographic group (U.S. Department of Health and Human Services, 2005). Six to ten percent of college undergraduates have seriously considered suicide in the past 12 months (Drum, Brownson, Burton, \& Smith, 2009; American College Health Association, 2007), while up to 24\% have thought about attempting suicide during their time in college (Westefeld et al., 2005). Given these concerns, knowledge of risk and protective factors for college students is becoming increasingly important as expectations that college and universities will prevent student suicide increase (Schwartz, 2006).

An accumulating body of studies have documented risk and protective factors associated with college students' suicidal behavior in recent years (Barrios, Everett, Simon, \& Brener, 2000; Kisch et al., 2005; Schwartz, 2006; Westefeld et al., 2005). Nevertheless, an important limitation of the college suicidality literature is the relative lack of attention to racial and ethnic minority college students' suicidal behavior (Stephenson, Belesis, \& Balliet, 2005). This gap in the literature is disconcerting, given the growing racial and ethnic diversity in U.S. college campuses; in 2005, racial and ethnic minority students constituted $31 \%$ of the student population in U.S. colleges and universities (National Center for Educational Statistics, 2008). Because of differences in cultural and racial socialization experiences, findings based on the general college population may not necessarily be generalizable to racial and ethnic minority students (Choi, Rogers, \& Werth, 2007). Therefore, the purpose of this multi-campus, national study was to 
examine risk and protective factors associated with one specific minority student group - Asian American college students.

Recently, the topic of Asian American college students' suicidal behavior has garnered considerable attention because of several high profile incidents and media reports. A recent news article published by Cornell University highlighted the fact that $62 \%$ of the 21 completed suicides at the university in the past decade were committed by students of Asian descent, whereas only $14 \%$ of the students at Cornell identified as Asian American (Ramanujan, 2006). Media reports of the deadliest college shooting in U.S. history at Virginia Tech University on April 17, 2007 also drew attention to the fact that the perpetrator, who committed suicide after the killings, was a Korean American male student (Kim, 2007).

Although there has been no published empirical study comparing the completed suicide rate of Asian American college students with that of other racial and ethnic student groups, several studies have found that Asian American college students reported higher levels of suicidal ideation than Caucasian American college students (Brener, Hassan, \& Barrios, 1999; Chang, 1998; Kisch, Leino, \& Silverman, 2005; Muehlenkamp, Gutierrez, Osman, \& Barrios, 2005). Moreover, evidence that racial and ethnic minority college students self-disclose suicidal ideation less readily than their European American counterparts (Morrison \& Downey, 2000) raises questions about whether studies on Asian American college students' suicidal ideation might underestimate the actual incidence of this problem.

Despite these concerns, only a handful of studies have examined risk and protective factors associated specifically with Asian American college students' suicidal ideation. For instance, several studies have found that indices of acculturation were related to Asian American 
college students' suicidal ideation (Davis, 1995; Ida, 1989; Jha, 2001). In the present study, we sought to extend this literature base by examining Asian American college students' suicidal ideation through the lens of Joiner's (2005) interpersonal theory of suicide.

\section{Interpersonal Theory of Suicide}

Joiner (2005) proposed an interpersonal theory of suicide that is based partly on the notion that the need to belong is a fundamental human motivation; consequently, suicide risk is reduced when this need is satisfied, whereas the thwarting of this need results in suicidal desire. Specifically, perceived burdensomeness and thwarted belongingness (the experience of being isolated from a valued social group) are viewed as two critical interpersonal factors contributing to suicidal desire (Joiner, 2005). Van Orden, Merill, \& Joiner (2005) reviewed several studies demonstrating that indicators of unmet interpersonal needs were related to suicide outcomes; for instance, living alone and being married have been shown to be suicide risk and protective factors respectively. Wong and Poon (2010) posited that Joiner's (2005) theory is particularly applicable to Asian Americans because its focus on thwarted interpersonal needs dovetails with several scholars' observation that suicide is viewed as a response to interpersonal stressors in Asian cultures (Range et al., 1999). Congruent with this view, Wong, Uhm, and Li (in press) found that family cohesion, an indicator of belongingness, was negatively associated with suicidal ideation in a national community sample of Asian American adults. Furthermore, a recent study found that a combination of perceived burdensomeness and thwarted belongingness was associated with elevated levels of suicidal ideation among Asian American college students (Wong, Koo, Tran, Chiu, \& Mok, 2011).

Goals of the Present Study 
Given this backdrop, we sought to apply the construct of belongingness in Joiner's (2005) interpersonal theory to the study of Asian American college students' suicidal ideation. We focused on indicators of belongingness because a sense of belongingness has been identified as a key factor in the adjustment of college students (see Lee \& Davis, 2000, for a review). Brener et al. (1999) found that among college students, being a member of a fraternity or sorority and living with a spouse or domestic partner reduced the odds of seriously considering attempting suicide. Living with a family member or partner might be a particularly salient protective factor for Asian American college students because family relationships and group orientation are important values in many collectivistic Asian cultures (Leong, Leach et al., 2007). Moreover, because student of color on college campuses often experience feelings of alienation and marginalization (Lee \& Davis, 2000; Tan, 1994), experiences that foster a sense of belonging on campus for Asian Americans may help protect against suicidal behavior. Consequently, in this study, we examined three indicators of belongingness: (a) living with a family member; (b) living with a partner; and (c) active participation in at least one student organization on campus. We predicted that these three indicators would be associated with reduced likelihood of suicidal ideation among Asian Americans.

In addition to indicators of belongingness, we also sought to examine several other demographic and psychosocial risk and protective factors that have been shown in previous research to be related to suicide outcomes. The investigation of these factors enabled us to test the extent to which indicators of belongingness independently predicted Asian American students' suicidal ideation beyond the influence of other risk and protective factors. We focused 
specifically on indicators of (a) mental health problems; (b) tobacco and alcohol use (c) gender; (d) academic performance; (e) grade classification; and (f) religious affiliation.

Mental Health Problems. Studies have shown that mental health problems are among the most robust predictors of suicide and suicidal ideation among college students (Furr et al., 2001; Schwartz \& Friedman, 2009; Stephenson et al., 2005). For example, in a study of Asian international students, Yang and Clum (1994) found that life stress, problem-solving confidence, social support, and hopelessness were indirectly associated with suicidal ideation through their relationship with depression. In the current study, we used participants' self-report of having taken medication for mental health reasons as a proxy indicator of mental health problems. We anticipated that this indictor would be positively related to an increased likelihood of suicidal ideation.

Tobacco and Alcohol Use. There is mounting evidence for the link between substance use and suicidal behavior (Westefeld et al., 2000). Specifically, tobacco and alcohol use have been found to be significant predictors of suicidal ideation among college students (Brener et al., 1999; Kisch et al., 2005). Substance use may foster suicidal behavior by enhancing impulsivity, reducing coping mechanisms, and impairing judgment (Brener et al., 1999; Westefeld et al., 2000) . We hypothesized that Asian American college students' use of tobacco and binge drinking would be related to an increased probability of suicidal ideation.

Gender. Although male college students are more likely to commit suicide than their female counterparts (Silverman, Meyer, Sloane, Raffel, \& Pratt., 1997), a study using a sample of college students indicated that women reported higher levels of suicidal ideation than men (Stephenson, Pena-Shaff, \& Quirk, 2006). Some scholars have proposed that, compared with 
male students, Asian American female students face unique stressors that might trigger suicidal behavior (Chung, 2003). These stressors include encountering the double oppression of racism and sexism, negative stereotypes about Asian American women (e.g., as subservient or sexuallypleasing women) that may have detrimental effects on self-esteem, dissatisfaction with one's body based on a White female standard of beauty, and the challenges of navigating female gender roles in traditional Asian American families (Kawahara \& Fu, 2007). Considering the higher suicidal ideation rates of female college students and the unique stressors that Asian American females face, we hypothesized that Asian American female students would more likely report suicidal ideation compared with Asian American male students.

Academic Performance. Poor academic performance has been implicated as a risk for college students' suicidal behavior (Furr, Westefeld, McConnell, \& Jenkins, 2001). Among Asian American college students, this problem might be particularly salient because they are frequently typecast as a model minority due of their perceived academic success (Ying \& Lee, 1999). This stereotype might result in enormous pressure on low-performing Asian American students to live up to others' expectations of their academic caliber (Choi et al., 2007; Hirabayashi, 2006; Leong, Leach, Yeh, \& Chou, 2007). Furthermore, compared with members of other racial and ethnic groups, Asian American college students experience greater parental expectations to do well academically; consequently, they may experience parental criticism or shame when they underperform academically (Castro \& Rice, 2003). In sum, the extant literature suggests that poor academic performance may be a salient mental health risk for Asian American students. Hence, we predicted that lower grade point averages (GPA) would be related to a greater likelihood of Asian American students reporting suicidal ideation. 
Grade Classification. In a nationally representative study of college students, Brener and colleagues (1999) found that students 18-24 years of age were more likely to report suicidal ideation than those above 24 years. This finding suggests that undergraduates may be at greater risk for suicidal ideation than graduate students. The experience of leaving home and separating from one's family, forming new social networks on campus, and grappling with identity issues common in emerging adulthood (Westefeld et al., 2006) might be a particularly stressful experience for Asian American undergraduates. Thus, we anticipated that Asian American undergraduate students would be at greater risk for suicidal ideation compared to Asian American graduate students.

Religious Affiliation. Colucci and Martin (2008) summarized research indicating that religious beliefs are associated with more negative attitudes about suicide as well as decreased suicidal ideation. Religious affiliation may be a protective factor because many religions include teachings that prohibit suicide (Dervic et al., 2004). Christian and Islamic teachings view suicide as morally objectionable. From the perspective of traditional Asian religions such as Taoism, Confucianism, and Buddhism, suicide is regarded as selfish and inappropriately passionate (Range et al., 1999). Hence, we surmised that having a religious affiliation would be related to reduced risk for suicidal ideation among Asian American college students.

In addition to the above risk and protective factors, we also analyzed the types of events that occurred before Asian American college students developed serious suicidal ideation in the past 12 months (e.g., recent family problems, breakup of a romantic relationship, etc.) to gain insight into common events that might be related to suicidal ideation among these individuals. In line with Joiner's (2005) interpersonal theory, we predicted that indicators of thwarted 
belongingness, such as family problems, a breakup of a romantic relationship, and a loss of friendship, would be the most frequently endorsed events occurring before the development of serious suicidal ideation.

\section{Method}

\section{Procedures and Participants}

The current study involved the analysis of archival survey data collected in 2006 through the National Research Consortium of Counseling Centers in Higher Education's study on the nature of suicidal crises in college students, an initiative that has enabled college counseling centers in the United States to collaborate on the study of college mental health. Participants received an email from their local college counseling center inviting them to fill out an online survey in exchange for the opportunity to participate in a drawing to win gift certificates from Amazon.com.

Using a stratified random sampling method, 108,500 students from 70 U.S. colleges and universities were invited to participate in the study. Diverse in geographical representation (20\% in the Northeast, $20 \%$ in the West, $30 \%$ in the Midwest, and 30\% in the South), the sample included participants from private $(38 \%)$ and public $(62 \%)$ institutions. The response rate was $25 \%$. For the purposes of our study, we analyzed data from participants who identified as Asian American (6.4\% of the total sample). The Asian American sample did not include students who identified with more than one racial background or students who identified as international students. After deleting the data of 13 participants who did not respond to the items on suicidal ideation, our final sample was comprised of 1,377 Asian American college students (average age 
$=23.11, \mathrm{SD}=5.49)$ across 66 colleges and universities in the United States. The survey did not include items on participants' Asian ethnic background and country of birth.

\section{Measures}

Participants completed a survey that included demographic questions as well as items about suicidal behavior and other salient variables. The survey items were drafted by the director of the National Research Consortium with input from directors of participating college counseling centers and feedback from two prominent experts in college suicidality. The majority of the items (66/89) consisted of dichotomous, forced-choice items. For the purposes of this study, only items relevant to our hypotheses were selected for analyses.

Two dichotomous, one-item measures were used to examine varying levels of severity in suicidality. In the first measure, participants who endorsed the following statements, "I wish this would all just end" and/or "I wish I was dead" in the past 12 months were classified as having morbid thoughts (yes/no). In our second measure, we used the item, "During the past 12 months, have you seriously considered attempting suicide? (yes/no)" to examine serious suicidal ideation. The predictor variables were measured using the following items in the survey: (a) "Have you ever taken medication for mental health concerns?" (yes/no), (b) tobacco use in the past 12 months (scale of 1 [never] to 6 [daily]); (c) binge drinking (defined as drinking 5 or more drinks of alcohol within a 24 hour period) in the past 12 months (scale of 1 [never] to 6 [daily]); (d) gender (male versus female); (f) GPA (0 - 4.0); (e) grade classification (undergraduate versus graduate); (f) religious affiliation (yes/no); (g) active participation in at least one student organization (yes/no) based on a list of 13 student organizations (e.g., professional, service, social, and religious organizations); (h) living with a family member 
(yes/no); and (i) living with a partner (yes/no). In addition, participants who reported that they had seriously considered attempting suicide in the past 12 months were asked to endorse which events from a list had occurred before they seriously considered suicide (see Table 2). Analyses

Hierarchical logistic regression was used to examine the relations between the predictor variables and outcome variables, morbid thoughts and serious consideration of suicide. Logistic regression is the method of choice for statistical analyses involving dichotomous outcome variables (Cizek \& Fitzgerald, 1999). Findings from logistic regression analyses are interpreted using an odds ratio $(O R)$. An $O R$ that exceeds 1.00 means that a 1-unit increase in the predictor variable is related to increased odds of the outcome variable occurring, whereas an $O R$ of less than 1.00 implies that a 1-unit increase is associated with decreased odds of the outcome variable occurring. One-tailed statistical tests were used because our hypotheses were directional. Listwise deletion was used to address missing data in some of the predictor variables (missing data did not exceed $1 \%$ of the total sample for any variable). Consequently, a sample of 1284 participants was used for the hierarchical logistic regression analyses.

Results

\section{Descriptive Statistics}

Forty-one percent of participants $(n=564)$ reported they had morbid thoughts in the past 12 months. Five percent $(n=66)$ reported they seriously considered committing suicide in the past 12 months. Among participants, 9.1\% $(n=125)$ had ever taken medication for mental health concerns, $27.3 \%(n=376)$ used tobacco in the past 12 months, $48.6 \%(n=666)$ engaged in binge drinking in the past 12 months, 60.1\% $(n=824)$ were female, 63.8\% $(n=877)$ were 
undergraduates, $77.9 \%(n=1072)$ participated actively in at least one student organization on campus, $14.5 \%(n=198)$ lived with a romantic partner, $29.6 \%(n=406)$ lived with a family member, and $63.4 \%(n=866)$ reported an affiliation with a specific religion $-10.3 \%(n=89)$ Buddhist, 58.2\% $(n=504)$ Christian, $21.4 \%$ Hindu $(n=185), 8.8 \%$ Muslim $(n=76)$, and 1.4\% $(n=12)$ other religions.

\section{Hierarchical Logistic Regression}

The following measures -- medication for mental health concerns, use of tobacco, binge drinking, gender, GPA, grade classification, and religious affiliation -- were entered in step one of the hierarchical logistic regression. In step two, the three indicators of belongingness - living with a family member, living with a partner, and active participation in at least one student organization -- were added.

Results of the hierarchical logistic regression analyses, including odds ratios, are presented in Table 1. With regard to morbid thoughts, the overall logistic regression model was significant, $\chi^{2}(10)=81.29, p<.001$. Nagelkerke $R^{2}$ indicated that $8 \%$ of the variance explaining morbid thoughts was accounted for by the variables in the model. In addition, the three indicators of belongingness contributed significantly to the overall model, block $\chi^{2}(3)=13.48, p=.004$. Consistent with our hypotheses, medication for mental health concerns, being female, low GPA and being an undergraduate were significantly associated with a greater likelihood of having morbid thoughts, whereas having a specific religious affiliation was significantly related to lower odds of having morbid thoughts. Tobacco use and binge drinking were not significantly associated with morbid thoughts. Among the indicators of belongingness, living with a partner and living with a family member were significantly related to lower odds of having morbid 
thoughts. Contrary to our prediction, the odds of having morbid thoughts increased significantly by $40 \%$ for participants who participated actively in at least one student organization.

With regard to serious consideration of suicide, the overall logistic regression model was significant, $\chi^{2}(10)=51.69, p<.001$. Nagelkerke $R^{2}$ indicated that $12 \%$ of the variance explaining morbid thoughts was accounted for by the variables in the model. Moreover, the three indicators of belongingness contributed significantly to the overall model, block $\chi^{2}(3)=13.24, p$ $=.004$. Consistent with our hypotheses, medication for mental health concerns and being an undergraduate were associated with a greater likelihood of seriously considering suicide. Gender, GPA, religious affiliation, tobacco use, and binge drinking were not significantly associated with seriously considering suicide. Among indicators of belongingness, living with a family member, but not living with a partner, was significantly related to lower odds of seriously considering suicide. However, participants who participated actively in at least one student organization were 3.44 times more likely to have seriously considered suicide compared with those who did not, a significant finding that was contrary to our hypothesis.

Because the significant positive relationships between active participation in student organizations and morbid thoughts and serious consideration of suicide were contrary to our hypotheses, we conducted several posthoc analyses to better understand these unexpected findings. First, because students within a particular college/university may be more similar to one another compared with students across different colleges/universities, we reran our analyses on morbid thoughts and serious consideration of suicide using generalized estimating equations (GEE) with logistic regressions to take into account this within-group correlation. The findings of both logistic regression analyses remain substantially similar to those of the original analyses; 
that is, all the predicted variables (including active participation) that were significantly associated with the outcome variables in the original logistic regressions remained significant in the same directions in the GEE logistic regressions.

In our second set of posthoc analyses, we considered the possibility that participation in specific student organizations may have had different relationships with suicidal ideation, i.e., participation in some organizations may have been a protective factor whereas participation in other organizations may have been a risk factor. Because participants indicated the specific student organizations they participated in (e.g., fraternities/sororities, religious organizations, etc.), we ran several logistic regression analyses using participation in the specific organizations as predictor variables in place of our generic active participation measure. Participation in specific organizations was either non-significantly or significantly and positively related to morbid thoughts and serious consideration of suicide. In none of these analyses was participation significantly and negatively related to morbid thoughts and serious consideration of suicide.

In our third set of posthoc analyses, we examined potential moderators of the relationship between active participation and suicidal ideation. Specifically, we considered the possibility that participants' gender or GPA might moderate the relations between active participation and suicidal ideation. We re-ran the logistic regression analyses for morbid thoughts and serious consideration of suicide with the addition of participation $\mathrm{x}$ gender and participation $\mathrm{x}$ GPA interactions. Both interaction effects were not significant. In sum, none of our posthoc analyses provided more information about the significant positive association between active participation in student organizations and suicidal ideation.

Events Occurring Before the Development of Serious Suicidal Ideation 
In addition to the hierarchical logistic regression analyses, we also conducted a descriptive analysis of the types of events that occurred before the development of serious suicidal ideation. Sixty-five of the sixty-six participants who reported they had seriously considered attempting suicide in the past 12 months responded to questions in the survey about the types of events that occurred before they developed serious suicidal ideation (see Table 2). Participants chose from a list of 12 events and were allowed to select more than 1 event. The three most frequently endorsed events were recent family problems $(47.7 \%)$, recent academic problems (43.1\%), and recent financial problems (24.6\%). Because family and academic problems were by far the most frequently endorsed events, we conducted a posthoc analysis of the proportion of participants who endorsed both events. Among participants who endorsed recent family problems, $58.1 \%(n=18)$ also endorsed recent academic problems.

\section{Discussion}

To our knowledge, this is the first multi-campus, national study to examine risk and protective factors associated with Asian American college student's suicidal ideation. Our findings provided partial support for Joiner's (2005) interpersonal theory of suicide. Two indicators of belongingness appeared to be protective factors against suicidal ideation. Living with a family member was found to be uniquely associated with lower odds of reporting morbid thoughts and serious suicide ideation, after controlling for several demographic and psychosocial variables. In addition, living with a partner was uniquely related to lower odds of reporting morbid thoughts, after controlling for other hypothesized predictor variables.

However, contrary to our hypotheses as well as previous research on college students' suicidal ideation (Brener et al., 1999), one indicator of belongingness -active participation in at 
least one student organization on campus -- was positively associated with a greater likelihood of having morbid thoughts and seriously considering suicide. None of our posthoc analyses shed light on these counter-intuitive findings. However, we speculated on two possible explanations. First, research has shown that exposure to racism constitutes a mental health risk (see Carter, 2007, for a review). Participating Asian American students who participated actively in student organizations may have come into contact with a greater number of students from other racial backgrounds. Consequently, their minority status may have resulted in greater and more distressing exposure to racism from other students. An alternative explanation is that a lack of active participation in student organizations might reflect the presence of protective factors not measured in the study. For instance, participating Asian Americans who were involved in other social organizations outside their college campuses might be less inclined to participate in college student organizations. It must be emphasized that these explanations are speculatory at best because in the present study, we did not have information about participants' subjective experience of participating in student organizations and about their participation in non-college organizations. Future research should investigate the relation between Asian Americans' participation in student organizations and suicidal behavior with the goal of identifying potential moderators and mediators of this relationship.

Several other hypothesized variables were associated with suicidal ideation. Consistent with our hypotheses, medication for mental health concerns (a proxy indicator for mental health problems), being female, low GPA, and being an undergraduate were significantly associated with a greater likelihood of having morbid thoughts in the past 12 months. Having a specific religious affiliation was significantly related to lower odds of having morbid thoughts. In 
addition, medication for mental health concerns and being an undergraduate were associated with a greater likelihood of seriously considering suicide in the past 12 months.

Among participating Asian American students who reported that they seriously considered attempting suicide in the past 12 months, the three most frequently endorsed events that occurred before the development of suicidal ideation were recent family problems, recent academic problems, and recent financial problems. Recent family problems (47.7\%) and recent academic problems $(43.1 \%)$ were by far the most frequently endorsed events. The prominence of family problems as the most frequently endorsed problem dovetails with the construct of thwarted belongingness in Joiner's (2005) interpersonal theory as well as previous research documenting a strong link between family conflict and suicidal behavior among Asian American adolescents (Lau, Jernewall, Zane, \& Myers, 2002).

However, the finding that academic problem was the second most frequently endorsed event preceding suicidal ideation stands in contrast to Furr et al.'s (2001) study of suicidal ideation in the general college population; in that study, problems with grades was the seventh most frequently endorsed problem (out of a list of nine problems) that contributed to suicidal ideation among students who reported suicidal ideation. Perhaps, academic problems might have been a particularly salient risk factor for participating Asian American students because of pressure to live up to others' stereotypes concerning Asian Americans' allegedly high-achieving academic abilities (Leong, Leach et al., 2007). It is also possible that family and academic problems might be two interrelated risk factors associated with Asian American college students' suicidal behavior (Choi et al., 2007). Indeed, among participating Asian American students who endorsed family problems as events preceding their suicidal ideation, $58.1 \%$ also endorsed 
academic problems. Participating Asian Americans with poor academic performance might have been more susceptible to parental criticism because of strong parental pressures to succeed academically (Castro \& Rice, 2003).

\section{Limitations}

Several limitations in our study should be noted. First, our reliance on cross-sectional data meant that caution had to be applied in drawing causal inferences about the relations between our predictor variables and suicidal ideation. For instance, although we identified low GPA as a potential risk factor associated with suicidal ideation among Asian American students, we could not definitively ascertain whether low GPA contributed to suicidal ideation or whether low GPA was a consequence of suicidal ideation. Future studies should use longitudinal research designs to examine the relations between potential risk and protective factors and suicidal behavior. Second, because the survey did not include items about participants' Asian ethnicities, generational statuses, and cultural experiences (e.g., acculturation), we could not explore ethnic and cultural differences in our sample of Asian American students.

Third, the use of one-item, dichotomous measures for many of our variables is a limitation because such measures do not capture different facets of a particular construct. For example, although living with a family member (yes/no) was found to be related to lower odds of suicidal ideation, we have insufficient information about how or why it might be a protective factor. Indeed, it is conceivable that for some Asian Americans, living with a family member can also be a stressful experience, given that family problems emerged as the most frequently endorsed event that occurred before the development of suicidal ideation. Finally, because this study focused exclusively on participating Asian American students' suicidal 
ideation, our analyses did not include any cross-cultural comparisons; accordingly, we do not know if our findings are generalizable to students from other racial and ethnic backgrounds.

\section{Practical Implications}

Notwithstanding these limitations, the results of our study present several practical implications. First, the list of events occurring before the onset of suicidal ideation endorsed by participants provides an indication of the stressors that might trigger suicidal behavior among Asian Americans. College mental health professionals who work with Asian American clients are urged to pay particular attention to the assessment and resolution of family, academic, and financial problems, the three most frequently endorsed events preceding suicidal ideation in our study. Additionally, our findings on risk factors can provide useful information for introducing primary suicide prevention interventions targeted at Asian American college students. Most college suicide prevention programs are either educational in nature (i.e., the provision of information about suicide to students) or crisis-oriented; however, more should be done to systematically identify and provide preventive interventions for at-risk students before the onset of suicidal behavior (Haas, Hendin, \& Mann, 2003).

Further, although the assessment of risk factors will always be an integral feature of suicide prevention interventions, it is important that college personnel do not neglect the nurturance of protective factors that serve as a buffer against suicidal ideation. In our study, having a specific religious affiliation, living with a partner, and living with a family member emerged as potential protective factors against suicidal ideation among Asian American college students. These findings point to the value of a systemic, strengths-based approach to college suicide prevention that might involve the collaboration of religious organizations, romantic 
partners, and family members. Finally, and perhaps most importantly, it is critical that college professionals do not adopt a one-size-fits-all suicide prevention strategy that neglects racial, ethnic, and cultural diversity. College professionals are encouraged to keep abreast of the emerging literature on suicidal behavior among racial and ethnic minority students (e.g., Choi et al., 2007; Morrison \& Downey, 2000; Stephenson et al., 2005) and to tailor their interventions accordingly. 


\section{References}

American College Health Association (2007, Fall). National College Health Assessment Reference Group Report. Retrieved January 16, 2009, from http://www.acha-ncha.org/docs/ACHANCHA_Reference_Group_Report_Fal12007.pdf.

Barrios, L. C., Everett, S. A., Simon, T. R., \& Brener, N. D. (2000). Suicide ideation among US college students: Associations with other injury risk behaviors. Journal of American College Health, 48, $229-233$.

Brener, N. D., Hassan, S. S., \& Barrios, L. C. (1999). Suicidal ideation among college students in the United States. Journal of Consulting and Clinical Psychology, 67, 1004-1008.

Carter, R. T. (2007). Racism and psychological and emotional injury: Recognizing and assessing racebased traumatic stress, The Counseling Psychologist, 35, 13-105.

Castro, J. R., \& Rice, K. G. (2003). Perfectionism and ethnicity: Implications for depressive symptoms and self-reported academic achievement. Cultural Diversity and Ethnic Minority Psychology, 9, 64-78.

Chang, E. C. (1998). Cultural differences, perfectionism, and suicidal risk in a college population: Does social problem solving still matter? Cognitive Therapy and Research, 22, 237-254.

Choi, J. J., Rogers, J. R., \& Werth, J. L. (2009). Suicide risk assessment with Asian American college students: A culturally informed perspective. The Counseling Psychologist, 37, 186-218.

Chung, I. W. (2003). Examining suicidal behavior of Asian American female college students: Implications for practice. Journal of College Student Psychotherapy, 18, 31-47.

Cizek, G. J., \& Fitzgerald, S. M. (1999). An introduction to logistic regression. Measurement and Evaluation in Counseling and Development, 31, 223-245. 
Colucci, E., \& Martin, G. (2008). Religion and spirituality along the suicidal path. Suicide and LifeThreatening Behavior, 38, 229-244.

Davis, W. G. (1995). Level of acculturation of Asian American adolescents as a predictor of depression and suicidal ideation. Dissertation Abstracts International, 56(05), $2859 \mathrm{~B}$.

Dervic, K., Oquendo, M. A., Grunebaum, M. F., Ellis, S., Burke, A. K., \& Mann, J. J. (2004). Religious affiliation and suicide attempt. American Journal of Psychiatry, 161, 2303-2308.

Drum, D., Brownson, C., Burton, A. \& Smith, S. (2009). New data on the nature of suicidal crises in college students: Shifting the paradigm. Professional Psychology: Research and Practice, 40, 213-222.

Furr, S. R., Westefeld, J. S., McConnell, G. N., \& Jenkins, J. M. (2001). Suicide and depression among college students: A decade later. Professional Psychology: Research and Practice, 32, 97-100.

Haas, A. P., Hendin, H., \& Mann, J. J. (2003). Suicide in college students, The American Behavioral Scientist, 46, 1224-1240.

Hirabayashi, K. E. (2006). The role of parental style on self-handicapping and defensive pessimism in Asian American college students. Dissertation Abstracts International, 66(11), 3928A

Ida, D. A. (1989). Depression, hopelessness, and suicide ideation among Asian-American students. Dissertation Abstracts International, 55 (01), 431B-432B.

Jha, A. (2001). Depression and suicidality in Asian Indian students. Dissertation Abstracts International, 62(03), 1311B.

Joiner, T. E., Jr. (2005). Why people die by suicide. Cambridge, MA: Harvard University Press. 
Kawahara, D. M., \& Fu, M. (2007). The psychology and mental health of Asian American women. In F. T. L. Leong, A. Ebreo, L. Kinoshita, A. G. Inman, \& L. H. Yang (Eds.), Handbook of Asian American Psychology (2nd ed., pp. 181-196). Thousand Oaks, CA: Sage Publications.

Kim, J. M. (2007). A push for caring imposition against passive tolerance: Reflections on the Virginia Tech massacre through a multicultural lens. Harvard Educational Review, 77, 354-359.

Kisch, J., Leino, E. V., \& Silverman, M. M. (2005). Aspects of suicidal behavior, depression, and treatment in college students: Results from the spring 2000 national college health assessment survey. Suicide and Life-Threatening Behavior, 35, 3-13.

Lau, A. S., Jernewall, N. M., Zane, N., \& Myers, H. F. (2002). Correlates of suicidal behaviors among Asian American outpatient youths. Cultural Diversity and Ethnic Minority Psychology, 8, 199213.

Lee, R. M., \& Davis, C., III (2000). Cultural orientation, past multicultural experience, and a sense of belonging on campus for Asian American college students. Journal of College Student Development, 41, 110-115.

Leong, F. T. L., Chang, D. F., \& Lee, S. (2007). Counseling and psychotherapy with Asian Americans: Process and outcomes. In F. T. L. Leong, A. Ebreo, L. Kinoshita, A. G. Inman, \& L. H. Yang (Eds.), Handbook of Asian American Psychology (2nd ed., pp. 429-447). Thousand Oaks, CA: Sage Publications.

Leong, F. T. L., Leach, M. M., Yeh, C., \& Chou, E. (2007). Suicide among Asian Americans: What do we know? What do we need to know? Death Studies, 31, 417-434. 
Morrison, L. L., \& Downey, D. L. (2000). Racial differences in self-disclosure of suicidal ideation and reasons for living: Implications for training. Cultural Diversity and Ethnic Minority Psychology, $6,374-386$.

Muehlenkamp, J. J., Gutierrez, P. M., Osman, A., \& Barrios, F. X. (2005). Validation of the positive and negative suicide ideations (PANSI) inventory in a diverse sample of young adults. Journal of Clinical Psychology, 61, 431-445.

National Center for Educational Statistics. (2008). Digest of Education Statistics, 2007. Retrieved October 15, 2008, from the National Center for Educational Statistics Web site: http://nces.ed.gov/fastfacts/display.asp?id=98

Ramanujan, K. (2006, April 19). Health expert explains Asian and Asian-American students' unique pressures to succeed. Cornell Chronicle Online. Retrieved October, 14, 2008, from http://www.news.cornell.edu/stories/april06/chung.ksr.html

Range, L. M., Leach, M. M., McIntyre, D., Posey-Deters, P. B., Marion, M. S., Kovac, S. H., et al. (1999). Multiple perspectives on suicide. Aggression and Violent Behavior, 4, 413-430.

Schwartz, A. J. (2006). College student suicide in the United States: 1990-1991 through 2003-2004. Journal of American College Health, 54, 341-352.

Silverman, M. M., Meyer, P. M., Sloane, F., Raffel, M., \& Pratt, D. M. (1997). The big ten student suicide study: A 10-year study of suicides on Midwestern university campuses. Suicide and LifeThreatening Behavior, 27, 285-303.

Stephenson, J. H., Belesis, M. P., \& Balliet, W. E. (2005). Variability in college student suicide: Age, gender, and race. Journal of College Student Psychotherapy, 19, 5-33. 
Stephenson, H., Pena-Shaff, J., \& Quirk, P. (2006). Predictors of college student suicidal ideation: Gender differences. College Student Journal, 40, 109-117.

Tan, D. L. (1994). Uniqueness of the Asian-American experience in higher education. College Student Journal, 28, 412-421.

U.S. Department of Health and Human Services. (2005). Deaths: leading causes for 2002 (National Vital Statistics Reports. Vol. 53). Hyattsville, MD: National Center for Health Statistics. (DHHS Publication No. 2005-1120).

Van Orden, K. A., Merill, K. A., \& Joiner, T. E. (2005). Interpersonal-psychological precursors to suicidal behavior: A theory of attempted and completed suicide. Current Psychiatric Review, 1, 187-196.

Van Orden, K. A., Witte, T. K., James, L. M., Castro, Y., Gordon, K. H., Braithwaite, S. R., Hollar, D. L., \& Joiner, T. E., Jr. (2008). Suicidal ideation in college students varies across semesters: The mediating role of belongingness. Suicide and Life Threatening Behavior, 38, 427-435.

Westefeld, J. S., Range, L. M., Rogers, J. R., Maples, M. R., Bromley, J. L., \& Alcorn, J. (2000). Suicide: An overview. The Counseling Psychologist, 28, 445-510.

Westefeld, J. S., Homaifar, B., Spotts, J., Furr, S., Range, L., \& Werth, J. L., Jr. (2005). Perceptions concerning college student suicide: Data from four universities. Suicide and Life-Threatening Behavior, 35, 640-645.

Westefeld, J. S., Button, C., Haley, J. T., Jr., Kettmenn, J. J., MacConnell, J., Sandil, R., et al. (2006). College student suicide: A call to action. Death Studies, 30, 931-956.

Wong, Y. J., Koo, K., Tran, K. K., Chiu, Y.-C., \& Mok, Y. (2011). Asian American college students' suicide ideation: A mixed-methods study. Journal of Counseling Psychology, 58, 197-209. 
Wong, Y. J., \& Poon, M.-L. (2010). Counseling Asian American men who demonstrate suicidal behavior. In W. M. Liu, D. Iwamoto \& M. Chae (Eds.), Culturally responsive counseling with Asian American men. (pp. 279-298). New York: Routledge.

Wong, Y. J., Uhm, S. Y., \& Li, P. (in press). Asian Americans' family cohesion and suicide ideation: Moderating and mediating effects. American Journal of Orthopsychiatry.

Yang, B., \& Clum, G. A. (1994). Life stress, social support, and problem-solving skills predictive of depressive symptoms, hopelessness, and suicide ideation in an Asian student population: A test of a model. Suicide and Life-Threatening Behavior, 24, 127-139.

Ying, Y., \& Lee, P. A. (1999). The development of ethnic identity in Asian-American adolescents: Status and outcome. American Journal of Orthopsychiatry, 69, 194-208. 
Table 1

Hierarchical Logistic Regression Analyses Predicting Morbid Thoughts and Serious Consideration of Suicide

\begin{tabular}{|c|c|c|c|c|c|c|}
\hline \multirow[b]{2}{*}{ Measures } & \multicolumn{3}{|c|}{ Morbid Thoughts } & \multicolumn{3}{|c|}{ Serious Consideration of Suicide } \\
\hline & $B$ & $S E$ & Odds Ratio & $B$ & $S E$ & Odds Ratio \\
\hline \multicolumn{7}{|l|}{ Step 1} \\
\hline Medication & 0.74 & 0.21 & $2.09 * *$ & 1.42 & 0.32 & $4.13 * *$ \\
\hline Use of tobacco & 0.05 & 0.05 & 1.05 & 0.11 & .09 & 1.11 \\
\hline Binge drinking & -0.05 & 0.05 & 0.95 & -0.12 & 0.11 & 0.89 \\
\hline Gender & 0.34 & 0.12 & $1.41 * *$ & .038 & 0.28 & 1.46 \\
\hline Grade point average & -0.49 & 0.13 & $0.62 * *$ & -.038 & 0.25 & 0.69 \\
\hline Grade classification & 0.45 & 0.13 & $1.57 * *$ & 1.06 & 0.37 & $2.89 * *$ \\
\hline Religious affiliation & -0.27 & 0.12 & $0.76^{*}$ & -.027 & 0.27 & 0.77 \\
\hline \multicolumn{7}{|l|}{ Step 2} \\
\hline Living with partner & -0.50 & 0.19 & $0.61 * *$ & -0.43 & 0.49 & 0.65 \\
\hline Living with family & -0.28 & 0.14 & $0.76^{*}$ & -0.51 & 0.29 & $0.60 *$ \\
\hline Participation & 0.34 & 0.15 & $1.40 *+$ & 1.24 & 0.43 & $3.44 * *+$ \\
\hline
\end{tabular}

Note. All measures are dichotomous except for grade point average, binge drinking, and use of tobacco. Medication = "Have you ever taken medication for mental health concerns?" Gender = female (coded as 1) versus male (coded as 0$)$; Grade classification = undergraduate (coded as 1$)$ versus graduate status (coded as 0 ); Participation = active participation in at least one student organization on campus (yes/no).

$* p<.05 * * p<.01$

+ Significant finding is contrary to hypothesis. 
Table 2

Participants' Endorsement of Events Occurring Before They Seriously Considered Attempting Suicide $(n=65)$

\begin{tabular}{lcc}
\hline Variable & $n$ & $\%$ \\
\hline Recent family problems & 31 & 48 \\
Recent academic problems & 28 & 43 \\
Recent financial problems & 16 & 25 \\
Recent breakup or loss of friendship & 14 & 22 \\
Recent breakup or loss of romantic relationship & 14 & 22 \\
Hurting yourself in a non-suicidal way (e.g., cutting) & 12 & 19 \\
Recent death of a friend/family member & 8 & 12 \\
Recent suicide of a friend/family member & 3 & 5 \\
Relationship violence & 3 & 5 \\
Recent trauma/victimization & 3 & 5 \\
Sexual assault & 1 & 2 \\
Recent conflict about sexual orientation & 1 & 2 \\
None of the above & 13 & 20 \\
\hline
\end{tabular}

